\title{
Digestion of tropical tree forages : influence of the level of Faidherbia albida pods in the ration on rumen in sacco peanut hay dry matter degradation in Gobra Zebu (Bos indicus)
}

\author{
$S$ Fall-Touré, E Traoré, D Friot \\ ISRA, LNERV, BP 2057, Dakar, Sénégal
}

In vivo digestion of browse plants based rations is influenced by their content in secondary compounds. Thus, variations in the digestibility of the rations according to browse level are reported by Miranda (1989, Monographie $n^{\circ} 7$ ILCA) and Fall (1993, Thes Doct Univ ENSAM, France). The non-additivity of the ration components owing to the occurrence of digestive interactions, suggested application of regression method rather than difference method to evaluate the in vivo digestibility of tree forage based rations.

To check the hypothesis of digestive interactions occurrence in the digestion of $F$. albida based rations, rumen cellulolytic capacity were measured in Zebu cattle fed with rations containing variable level of $F$. albida pods.

Cellulolytic capacity of rations was evaluated by measuring rumen in sacco dry matter degradation (DMD) of a standard feed, peanut hay, in Gobra Zebu at the LNERV station of ISRA (Dakar, Sénégal). Mature $F$. albida pods, collected in the Senegalese groundnut basin during the fresh dry season in 1994, were included in the ration of Gobra Zebu at a level varying from 0 to $75 \%$ of the total ration. The basal diet was made of rice straw and peanut cake in the constant proportion of 85/15 (w/w). To avoid the influence of intake level in the digestion, cattle were fed on a restricted basis of $55 \mathrm{~g} / \mathrm{kg} \mathrm{LW} 0.75$ for all tested rations.

In sacco method were applied according to the procedure described by Michalet-Doreau et al, (1987, Bull Tech CRZV Theix, INRA France, $69,5-7)$. Used nylon material was of $46 \mu \mathrm{m}$ regular pore size. Four incubation times spread between 0 and 72 hours were tested. After incubation in the rumen, bags were washed under a running water at room temperature ; bacterial decontamination of rumen residues were performed using stomacher by the procedure of Ould-Bah and Michalet-Doreau (1989, Proc XVI Int Grassld Congr, 909-910).

The influence of level of $F$. albida pods in the ration on peanut hay DMD profile was appreciated using analysis of variance.

Mean in sacco dry matter degradation of peanut hay were $31.8,54.6,63.8$ and $64.6 \%$ DM respectively at $4,24,48$ and 72 hours incubation time.

The influence of $F$. albida pods level on peanut hay in sacco DMD were not significant whatever the ration type and the incubation time. Those results indicate constant and good cellulose digestion in the rumen of zebu cattle fed with increasing amount of $F$. albida pods suggesting non occurrence of digestive interactions in the tested diets. Those observations can be explained by low precipitating tannins content of $0.72 \%$ DM in $F$. albida pods as reported by Grillet and Villeneuve (1994, CIRAD-EMVT report Program ST2, 89, 215). That concentration is below the critical level of $5 \%$ and thus, does not have harmful effect when fed to ruminants (Mangan, 1988, Nutr Res Rev, 1, 209-231). To confirm that result current trials investigate the variation profile of in vivo dry matter digestibility of $F$. albida pods based rations in Peul-peul sheep.

\begin{tabular}{lcccccc}
\hline Pods in the diet (\%) & 0 & 15 & 30 & 50 & 75 \\
Incubation time (hours) & & & & & & \\
4 & 32.7 & 32.6 & 31.4 & 27.8 & 34.5 \\
24 & 57.7 & 50.1 & 58.0 & 50.8 & 56.4 \\
48 & 64.5 & 63.5 & 64.2 & 61.3 & 65.6 \\
72 & 65.8 & 64.6 & 65.6 & 60.7 & 66.3 \\
\hline
\end{tabular}

